\title{
Changes in Cardiac Myofibrillar ATPase Activity during Development of Hyperthyroidism in the Rabbit
}

\author{
Satoshi Takeo, Ph.D., Eiji Tomomatsu, M.D., * and \\ Matao Sakanashi, M.D.
}

\begin{abstract}
SUMmary
This study examined changes in cardiac myofibrillar ATPase activity during the development of hyperthyroidism and the relationships between changes in myofibrillar ATPase activity and hemodynamic parameters in rabbits. Calcium-stimulated, magnesium-dependent ATPase (Ca-ATPase) activity of cardiac myofibrils exhibited about a $30 \%$ increase after the first week of treatment with excess desiccated thyroid tissue powder (thyroid-treatment) and did not show further increase during thyroid-treatment. Development of cardiac hypertrophy and increases in systolic and diastolic blood pressure were dependent upon prolonged periods of thyroid-treatment lasting from 3 days to 4 weeks, whereas the maximal increase (about 55\%) in heart rate was seen after the first week of thyroid-treatment. The elevated level lasted throughout subsequent thyroid-treatment. Lineweaver-Burk plots showed an increase in $\mathrm{Km}$ and $\mathrm{Vmax}$ values for Ca-ATPase activity of myofibrillar preparation from the thyrotoxic hearts of treated animals. Increased Ca-ATPase activity was correlated with thyroid-induced changes in heart rate. Propranolol partially reduced the thyroidinduced increase in $\mathrm{Ca}-\mathrm{ATP}$ ase activity and heart rate, suggesting participation of beta-adrenoceptors in the thyroid-induced increases of Ca-ATPase activity and heart rate.
\end{abstract}

\section{Additional Indexing Words:}

Cardiac hypertrophy

Heart rate

Hyperthyroidism

Myofibrillar ATPase

hormone

Propranolol

Systemic blood pressure Thyroid

\footnotetext{
A

DMINISTRATION of excess thyroid hormone has been demonstrated to induce cardiovascular changes such as increases in heart rate, sys-

From the Department of Pharmacology, School of Medicine, Faculty of Medicine, University of the Ryukyus, Okinawa and *the Dcpartment of Pharmacology, Kumamoto University Medical School, Kumamoto.

Address for reprint: Matao Sakanashi, M.D., Department of Pharmacology, School of Medicine, Faculty of Medicine, University of the Ryukyus, Okinawa 903-01, Japan.

Received for publication March 12, 1983.
} 
temic blood pressure, cardiac output, and speed of muscle contraction, including cardiac hypertrophy. ${ }^{\text {) }}$ An increase in calcium stimulated ATPase activity of cardiac contractile protein has been observed under the experimental hyperthyroidism, after the pathophysiological stage of hyperthyroidism is fully developed. ${ }^{2-8)}$ Although the physiological nature of calcium stimulated ATPase of cardiac myosin is considered to be directly or indirectly related to changes in hemodynamic parameters, little information is available concerning the correlation between ATPase activity of cardiac myofibrils and cardiovascular parameters during the pathogenesis of hyperthyroidism. Furthermore, the biochemical alterations in heart subcellular fractions which have been observed in several experimental myocardial preparations are generally conceived to depend upon the degree and the type of the cardiac failure. ${ }^{91}$ Thus, in an attempt to explore possible mechanisms for the genesis of thyroid-induced pathophysiological changes, the present study was designed (1) to examine the time-course of changes in heart rate, systemic blood pressure, and ATPase activity of cardiac myofibrils during the development of hyperthyroidism, and (2) to ascertain correlations between the cardiovascular parameters and the biochemical activity of cardiac myofibrils. We also examined whether adrenergic activity may be involved in the thyroid-induced biochemical and physiological alterations, since there are several arguments implicating sympathetic activity in the development of hyperthyroidism. ${ }^{3 /, 10)-12)}$

\section{Methods}

Fifty-nine albino rabbits of either sex, weighing about $2 \mathrm{Kg}$, were used in the present experiment. Rabbits were fed with a bean-curd refuse containing $250 \mathrm{mg} / \mathrm{Kg} /$ day desiccated thyroid tissue powder (purchased from Teikoku Zoki; containing $0.30-0.35 \%$ iodine as an organic compound) (thyroid-treatment). After ensuring that the animal took all of the food containing thyroid tissue powder, commercially available, normal diet was provided. Administration of thyroid tissue powder continued for periods of time lasting from 3 days to 4 weeks. Some animals also received subcutaneous injections of either $5 \mathrm{mg} / \mathrm{Kg}$ phentolamine or $2 \mathrm{mg} / \mathrm{Kg}$ propranolol in the early morning and in the late afternoon. Control rabbits were treated with the normal diet (without thyroid tissue powder) and were injected with physiological saline. The treatment with thyroid tissue powder and/or other agents was not performed on the day when hemodynamic parameters and myofibrillar ATPase activity were examined. Another set of experiments was designed to examine biochemical and hemodynamic factors during recovery from hyperthyroidism. Rabbits were treated with normal diet for 4 weeks after the cessation of the 
thyroid-treatment for 4 weeks, and hemodynamic parameters, the degree of cardiac hypertrophy and myofibrillar ATPase activity were subsequently measured.

\section{Measurement of hemodynamic parameters:}

Animals were anesthetized with intravenous injection of $1 \mathrm{Gm} / \mathrm{Kg}$ urethan. The trachea was cannulated to prevent airway obstruction. The arterial blood pressure was recorded using an electronic manometer (Nihonkoden MT-4T) through a polyethylene tube inserted into left femoral artery. The heart rate was measured with a cardiotachometer (Nihonkoden RM-45, PMP-3004). Then, the heart was dissected quickly and placed into cold $0.3 \mathrm{M}$ sucrose solution containing $10 \mathrm{mM}$ Tris- $\mathrm{HCl}, \mathrm{pH}$ 7.0. The hearts were weighed for estimation of cardiac hypertrophy.

Preparation of mvofibrils:

After measurements of hemodynamic parameters of hyperthyroid and euthyroid rabbits, myofibrils were prepared from the ventricles according to the method of Solaro et al. ${ }^{13)}$ Ventricles were cut into small pieces with scissors, and homogenized in a solution containing $0.3 \mathrm{M}$ sucrose and $10 \mathrm{mM}$ imidazole $(\mathrm{pH} 7.0)$ with an ultra-turax for $30 \mathrm{sec}$. The homogenate was centrifuged at $17,300 \mathrm{Gm}$ for $20 \mathrm{~min}$. The pellet was suspended with a glassteflon homogenizer in a solution of the following composition: $60 \mathrm{mM} \mathrm{KCl}$,

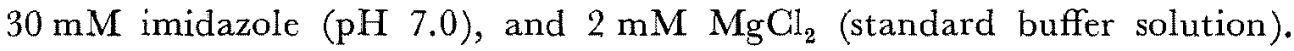
The suspension was centrifuged at $750 \mathrm{Gm}$ for $15 \mathrm{~min}$. The sequence of resuspension, homogenization, and centrifugation was repeated 4 more times. The resulting pellet was suspended in the standard buffer solution additionally containing $2 \mathrm{mM}$ EGTA and centrifuged at $750 \mathrm{Gm}$ for $15 \mathrm{~min}$. Further purification of the myofibrils was achieved by suspending the pellet in standard buffer solution containing 1\% Triton X-100. The suspension was then centrifuged at $750 \mathrm{Gm}$ for $15 \mathrm{~min}$. Triton X-100 treatment was repeated once. The resulting pellet was washed 4 times with the standard buffer solution. The purified myofibrils werc finally suspended in the standard buffer solution at a protein concentration of $6-8 \mathrm{mg} / \mathrm{ml}$. Protein concentrations were determined by the method of Lowry et al. ${ }^{14)}$

ATPase assay:

The details of the ATPase assay were described previously. ${ }^{15)}$ Magnesium-dependent ATPase (Mg-ATPase) activity of cardiac myofibrils was measured at $37^{\circ} \mathrm{C}$ in $1 \mathrm{ml}$ of the medium containing $50 \mathrm{mM} \mathrm{KCl}, 20 \mathrm{mM}$ im-

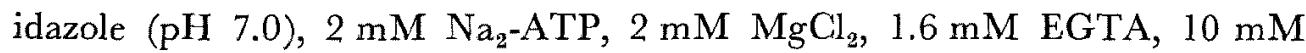
$\mathrm{NaN}_{3}$, and about $0.7 \mathrm{mg}$ myofibrillar protein, unless otherwise mentioned. Total ATPase activity was determined at $37^{\circ} \mathrm{C}$ in $1 \mathrm{ml}$ of the buffer containing $50 \mathrm{mM} \mathrm{KCl}, 20 \mathrm{mM}$ imidazole ( $\mathrm{pH} 7.0$ ), $2 \mathrm{mM} \mathrm{Na}_{2}-\mathrm{ATP}, 2 \mathrm{mM} \mathrm{MgCl}_{2}$, 
$0.1 \mathrm{mM} \mathrm{CaCl}_{2}, 10 \mathrm{mM} \mathrm{NaN}_{3}$, and about $0.7 \mathrm{mg}$ myofibrillar protein. The reaction was initiated by addition of $\mathrm{ATP}$ and, 2 min later, terminated by addition of $1 \mathrm{ml}$ of $12 \%$ trichloroacetic acid. Preliminary studies showed that both Mg-ATPase and total ATPase activities increased almost linearly during 5 min of incubation under these assay conditions. The reaction mixture was centrifuged at $1,000 \mathrm{Gm}$ for $10 \mathrm{~min}$ at $0-4^{\circ} \mathrm{C}$, and the supernatant was assayed for inorganic phosphate liberated by the method of Taussky and Shorr. ${ }^{16)}$ The difference in the activities between total ATPase and $\mathrm{Mg}$ ATPase is taken as calcium stimulated, magnesium-dependent ATPase (CaATPase) activity.

Statistical significance:

Statistical significance was evaluated using Student's t-test. P value of less than 5\% was considered to be significant. Regression lines were calculated by the method of least squares, and coefficients of correlation were calculated using Pearson's moment formula.

\section{Results}

In a preliminary study, we examined effects of various doses of thyroid tissue powder on cardiac myofibrillar ATPase activity and hemodynamic parameters of the rabbit. Myofibrillar Ca-ATPase activities of rabbits treated orally for 2 weeks with 0 (control), $2.5,25$, and $250 \mathrm{mg} / \mathrm{Kg} /$ day thyroid tissue powder were 354, 341, 324, and 449 nmoles $\mathrm{Pi} / \mathrm{mg}$ protein/2 min (mean values of 2 experiments). By contrast, myofibrillar Mg-ATPase activity was unaffected by thyroid-treatment (149-156 nmoles $\mathrm{Pi} / \mathrm{mg}$ protein/2 min, $\mathrm{n}=2$ ). The heart rate was not affected by the treatment with 2.5 and $25 \mathrm{mg} / \mathrm{Kg} / \mathrm{day}$ thyroid tissue powder, but it was increased by the treatment with $250 \mathrm{mg}$ / $\mathrm{Kg} /$ day thyroid tissue powder ( $157 \%$ of the control), Dose-related increases in systolic and diastolic blood pressure (130/86, 142/92, and 168/105 $\mathrm{mmHg}$ / $\mathrm{mmHg}$ ) were seen upon treatment with $2.5,25$, and $250 \mathrm{mg} / \mathrm{Kg} /$ day thyroid tissue powder, respectively (control value was $126 / 85 \mathrm{mmHg} / \mathrm{mmHg}$ ). Thus, we employed desiccated thyroid tissue powder at a dose of $250 \mathrm{mg} / \mathrm{Kg} /$ day for the subsequent experiments. Triiodothyronine concentration in the blood of the rabbits treated with $250 \mathrm{mg} / \mathrm{Kg} /$ day of thyroid tissue powder for 2 weeks, measured by commercially available method (AMERLEX, Kakenkagaku) ${ }^{17}$ was $6.2 \pm 0.7 \mu \mathrm{g} / \mathrm{L}$ (a mean \pm S.E.M. of 4 experiments), which was 6 times higher than the control value $(1.0 \pm 0.2 \mu \mathrm{g} / \mathrm{L}, \mathrm{n}=4)$. The body weight of rabbits treated with $250 \mathrm{mg} / \mathrm{Kg} /$ day thyroid tissue powder for 2 weeks increased slightly (less than $5 \%$ ), whereas the body weight of the control rabbits showed $3-12 \%$ increase in comparison with the initial value. The heart 
Table I. Systemic Blood Pressure, Heart Rate, Cardiac Hypertrophy Index and Myofibrillar ATPase Activity at Various Stages of Thyroid-Treatment

\begin{tabular}{|c|c|c|c|c|c|c|}
\hline & \multirow{2}{*}{ Control } & \multicolumn{4}{|c|}{ Thyroid-treatment } & \multirow{2}{*}{$\begin{array}{l}\text { Recovery } \\
\text { 4th week }\end{array}$} \\
\hline & & 3rd day & Ist week & 2nd week & 4th week & \\
\hline Number of experiments & 8 & 6 & 6 & 6 & 6 & 4 \\
\hline \multicolumn{7}{|l|}{ Blood pressure (mmHg) } \\
\hline Systolic & $125 \pm 3$ & $119 \pm 4$ & $146 \pm 9 *$ & $171 \pm 7 *$ & $206 \pm 12^{*}$ & $134 \pm 6$ \\
\hline Diastolic & $87 \pm 1$ & $84 \pm 5$ & $86 \pm 5$ & $104 \pm 3^{*}$ & $117 \pm 5^{*}$ & $91 \pm 4$ \\
\hline Heart rate (beats/min) & $261 \pm 6$ & $378 \pm 8^{*}$ & $406 \pm 9 *$ & $411 \pm 15^{*}$ & $407 \pm 23 *$ & $274 \pm 10$ \\
\hline \multicolumn{7}{|l|}{ Hypertrophy $\left(\mathrm{Gm} / \mathrm{Kg} \times 10^{3}\right)$} \\
\hline Heart weight/body weight & $2.1 \pm 0.1$ & $2.5 \pm 0.1^{*}$ & $2.8 \pm 0.2 *$ & $3.3 \pm 0.2^{*}$ & $3.8 \pm 0.1 *$ & $2.3 \pm 0.1$ \\
\hline $\begin{array}{l}\text { Ventricular weight/body } \\
\text { weight }\end{array}$ & $1.3 \pm 0.1$ & $1.6 \pm 0.1 *$ & $1.9 \pm 0.1^{*}$ & $2.1 \pm 0.1$ & $2.5 \pm 0.1 *$ & $1.6 \pm 0.1 *$ \\
\hline \multicolumn{7}{|l|}{$\begin{array}{l}\text { Myofibrillar ATPase } \\
\text { (nmoles } \mathrm{Pi} / \mathrm{mg} \text { protein/min) }\end{array}$} \\
\hline Mg-ATPase & $73 \pm 6$ & $55 \pm 7 *$ & $77 \pm 10$ & $70 \pm 6$ & $77 \pm 13$ & $50 \pm 7^{*}$ \\
\hline Ga-ATPase & $171 \pm 5$ & $182 \pm 5$ & $225 \pm 7 *$ & $226 \pm 6^{*}$ & $229 \pm 12^{*}$ & $167 \pm 10$ \\
\hline
\end{tabular}

Each value represents mean \pm S.E.M. of the experiments. * Significantly different from the control value $(p<0.05)$. Values in the recovery group were obtained from the rabbit 4 weeks after cessation of thyroid treatment.

weights of the control rabbits ranged from 4.6 to $5.2 \mathrm{Gm}$, while those of thyroid tissue powder-treated were 4.9 to $6.0 \mathrm{Gm}$.

Cardiovascular effects:

Changes in systemic blood pressure, heart rate and cardiac hypertrophy during the development of hyperthyroidism are summarized in Table I. The systolic blood pressure increased significantly during the first week of thyroidtreatment. Diastolic blood pressure also increased significantly during the second week of thyroid-treatment. Both systolic and diastolic blood pressure returned to the control level by the 4 th week after the cessation of the thyroidtreatment. Heart rate increased significantly by the third day of thyroidtreatment and reached $155 \%$ of the control value at the end of the first week. Thyroid-induced increment in heart rate was maintained throughout the successive thyroid-treatment. The heart rate returned to the initial control level by the 4 th week after the cessation of thyroid-treatment. The ratios of wet heart weight $(\mathrm{Gm})$ /body weight $(\mathrm{Kg})$ and wet weight of left ventricles $(\mathrm{Gm}) /$ body weight $(\mathrm{Kg}) /$ were taken as indices of cardiac hypertrophy induced by thyroid-treatment. Significant increases in these indices of cardiac hypertrophy were seen at all stages of thyroid-treatment. The elevation in the ratios of heart weight to body weight was restored almost to the initial control level by the 4 th week after the cessation of thyroid-treatment. However, the ratio of the left ventricular weight to body weight was slightly higher (23\%) than 


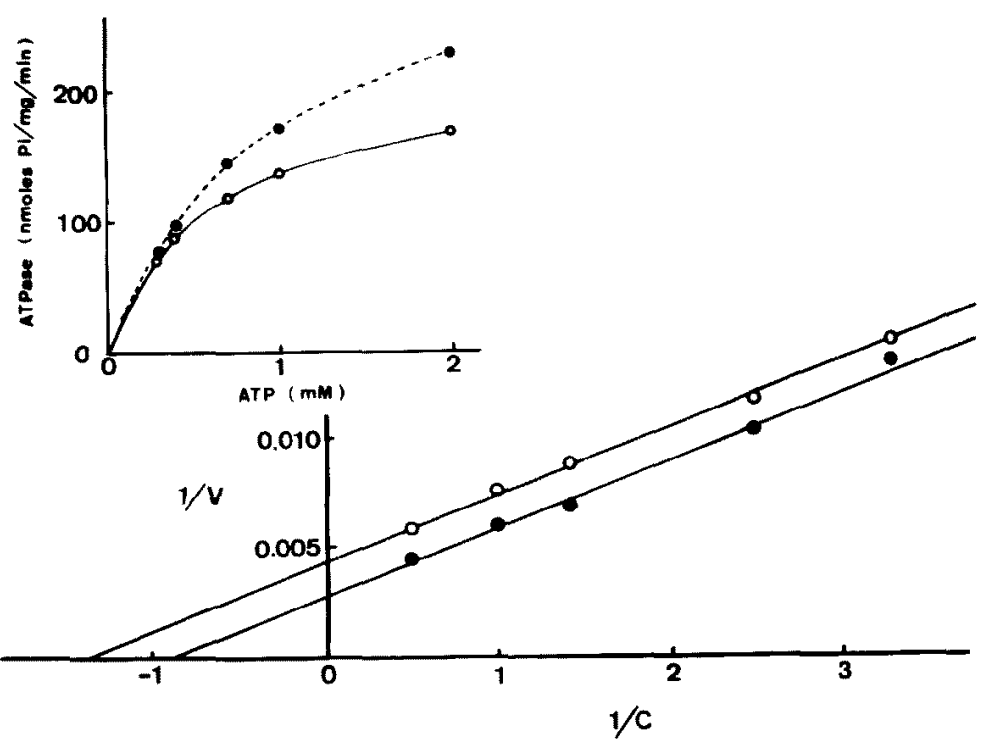

Fig. 1. Cardiac myofibrillar Ca-ATPase activity of the control rabbits (O) and the rabbits treated with $250 \mathrm{mg} / \mathrm{Kg} /$ day thyroid for 2 weeks (O) at different concentrations of ATP $(0.3$ to $2 \mathrm{mM})$ and their Lineweaver-Burk plots. The ATPase activity was measured at $37^{\circ} \mathrm{C}$ for $2 \mathrm{~min}$ in the medium described in the Methods section, and was expressed as nmoles $\mathrm{Pi} / \mathrm{mg}$ protein/ $\min$.

the control value, but markedly lower than the value after 4 weeks of thyroidtreatment.

Changes in myofibrillar A TPase activity:

Ghanges in myofibrillar ATPase activity during the development of hyperthyroidism are also shown in Table I. The Mg-ATPase activity of cardiac myofibrils was slightly lower than the value on the 3rd day of thyroid-treatment and in the 4th week after the cessation of the treatment. However, the Mg-ATPase activity was essentially the same during thyroid-treatment. In contrast, Ca-ATPase activity was increased by the treatment with thyroid tissue powder. Significant increase $(30 \%)$ in Ca-ATPase activity was seen after the first week of thyroid-treatment and this difference was maintained throughout the course of thyroid-treatment. The Ca-ATPase activity returned to the initial control level by the 4th week after the cessation of thyroid-treatment.

The cardiac myofibrillar Ca-ATPase activity of rabbits treated with thyroid tissue powder for 2 weeks was measured at different concentrations of ATP $(0.3$ to $2 \mathrm{mM})$ and the Lineweaver-Burk plots of the results were compared with control animals (Fig. 1). The $\mathrm{Km}$ value increased from 0.7 (control) to $1.1 \mathrm{mM}$ ATP after thyroid-treatment and the $\mathrm{V}_{\max }$ also increased 


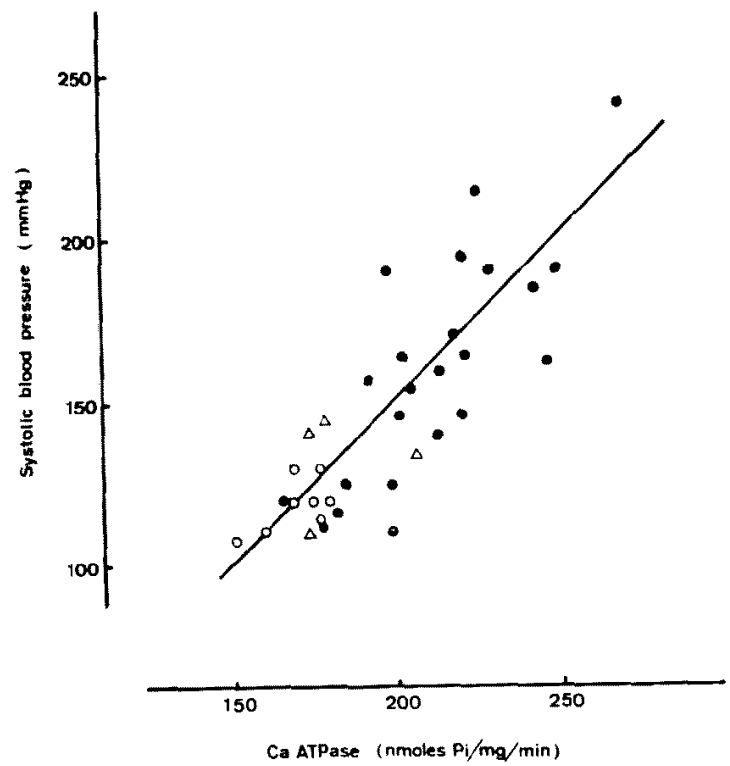

Fig. 2. Relationship between cardiac myofibrillar Ca-ATPase activity and systolic blood pressure of the control rabbits (O), the rabbits treated with $250 \mathrm{mg} / \mathrm{Kg} / \mathrm{day}$ thyroid for 3 days to 4 weeks (O) and the rabbits at the 4 th week after the cessation of thyroid-treatment $(\Delta)$. The ATPase activity was measured at $37^{\circ} \mathrm{C}$ in the medium described in the Methods section and was expressed as nmoles $\mathrm{Pi} / \mathrm{mg}$ protein/min. The regression line: $\mathrm{Y}=0.99 \mathrm{X}+50$. The coefficient of the correlation: $r=0.83, p<0.05$.

from 220 to 350 nmoles $\mathrm{Pi} / \mathrm{mg}$ protein.

Relationship between the Ca-ATPase activity and cardiovascular effects:

In thyroid tissue powder-treated rabbit hearts (Fig. 2), the Ca-ATPase activity was significantly correlated with changes in systolic blood pressure $(\mathrm{r}=0.83, \mathrm{p}<0.05)$; it was not correlated with the diastolic pressure. A significant correlation of the Ca-ATPase activity with heart rate was also observed when these parameters of both the control and thyroid tissue powdertreated rabbits were pooled $(r=0.81, p<0.05)$ (Fig. 3). It is of great interest that the regression lines of the Ca-ATPase activities against heart rate of the control, the thyroid tissue powder-treated and the recovery group were well correlated within each group $(r=0.86,0.86$, and 0.95 , respectively). Furthermore, these three lines calculated were nearly parallel with slopes ranging from 0.94 to 1.13. By contrast, there was no significant correlation of the increased Ca-ATPase activity with cardiac hypertrophy indices of the rabbits (heart weight/body weight and left ventricular weight/body weight).

Treatment with either phentolamine or propranolol:

In order to ascertain whether thyroid-induced changes in myofibrillar ATPase activity, hemodynamic parameters and cardiac hypertrophy index in 


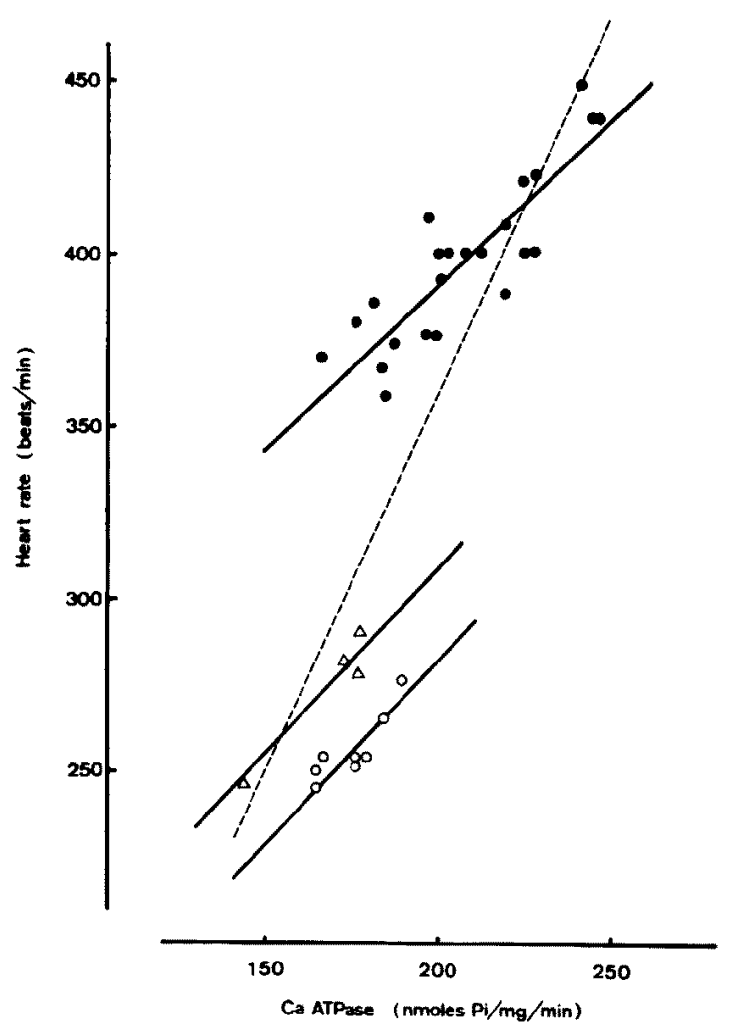

Fig. 3. Relationship between cardiac myofibrillar Ca-ATPase activity and heart rate of the control rabbits (O), the rabbits treated with $250 \mathrm{mg} / \mathrm{Kg}$ / day thyroid for 3 days to 4 weeks (O) and rabbits at 4 weeks after the cessation of thyroid treatment for 4 weeks $(\Delta)$. The AT Pase activity was measured at $37^{\circ} \mathrm{C}$ for $2 \mathrm{~min}$ in the medium described in the Methods section, and was expressed as nmoles $\mathrm{Pi} / \mathrm{mg}$ protein/min. The dashed regression line was calculated using all parameters derived from the control, thyroid-treated and recovery groups: $\mathrm{Y}=2.2 \mathrm{X}-80$, while solid regression lines were calculated using parameters of each control, thyroid-treated and recovery group, respectively; $\mathrm{Y}=1.06 \mathrm{X}+70, \mathrm{Y}=0.94 \mathrm{X}+202, \mathrm{Y}=1.13 \mathrm{X}+86$, respectively. The coefficients of correlation of the control, thyroid-treated, and recovery groups were $r=0.86,0.86$, and 0.95 , respectively. These values were statistically significant $(\mathrm{p}<0.05)$.

the present experiments are mediated through stimulation of adrenergic receptor activity, phentolamine (an adrenergic alpha-antagonist) and propranolol (an adrenergic beta-antagonist) were employed in combination with thyroid-treatment (Table II). Treatment of rabbits with $10 \mathrm{mg} / \mathrm{Kg} /$ day phentolamine or $4 \mathrm{mg} / \mathrm{Kg} /$ day propranolol per se for 2 weeks did not alter any biochemical or hemodynamic parameters examined in the present experiment. Although there was a slight difference in diastolic blood pressure between the rabbits treated with thyroid tissue powder and thyroid tissue pow- 
Table II. Systemic Blood Pressure, Heart Rate, Gardiac Hypertrophy Index and Myofibrillar ATPase Activity of the Rabbits Treated with $250 \mathrm{mg} / \mathrm{Kg} /$ day Thyroid, $4 \mathrm{mg} / \mathrm{Kg} / \mathrm{day}$ Propranolol, $10 \mathrm{mg} / \mathrm{Kg} /$ day Phentolamine, and the Thyroid in Combination with Either Propranolol or Phentolamine for 2 Weeks

\begin{tabular}{l|c|c|c|c}
\hline & $\begin{array}{c}\text { Thyroid } \\
\text { Propranolol }\end{array}$ & $\begin{array}{c}\text { Thyroid } \\
\text { Phentolamine }\end{array}$ & Propranolol & Phentolamine \\
\hline $\begin{array}{l}\text { Number of experiments } \\
\text { Blood pressure (mmHg) }\end{array}$ & 6 & 6 & 4 & 4 \\
Systolic & $165 \pm 12^{*}$ & $159 \pm 10^{*}$ & $126 \pm 2$ & $130 \pm 4$ \\
$\begin{array}{l}\text { Diastolic } \\
\text { Heart rate (beats/min) }\end{array}$ & $102 \pm 6^{*}$ & $91 \pm 5$ & $86 \pm 2$ & $84 \pm 4$ \\
Hypertrophy (Gm/Kg $\left.\times 10^{3}\right)$ & $378 \pm 13^{*} \#$ & $431 \pm 23^{*}$ & $280 \pm 15$ & $264 \pm 10$ \\
$\begin{array}{l}\text { Heart weight/body weight } \\
\text { Ventricular weight/body } \\
\text { weight }\end{array}$ & $3.4 \pm 0.1^{*}$ & $3.1 \pm 0.1^{*}$ & $2.1 \pm 0.1$ & $2.2 \pm 0.1$ \\
Myofibrillar ATPase \\
(nmoles Pi/mg protein/min) \\
$\begin{array}{l}\text { Mg-ATPase } \\
\text { Ca-ATPase }\end{array}$ & $2.3=0.1^{*}$ & $2.1 \pm 0.1^{*}$ & $1.4 \pm 0.1$ & $1.5 \pm 0.2$ \\
& $189 \pm 3^{*} \#$ & $210 \pm 11^{*}$ & $170 \pm 7$ & $169 \pm 9$
\end{tabular}

Each value represents mean \pm S.E.M. of the experiments. * and \# indicate a significant difference $(\mathrm{p}<0.05)$ from values of the control and thyroid-treated groups which are shown in Table I, respectively.

der plus phentolamine for 2 wecks, thyroid-induced increases in systolic blood pressure, heart rate, cardiac hypertrophy index, and myofibrillar Ca-ATPase activity were not modified significantly by phentolamine-treatment. It is noteworthy that the heart rate and cardiac myofibrillar Ca-ATPase activity were significantly lower in rabbits treated with thyroid tissue powder and propranolol than in animals given thyroid tissue powder only. However, they still exceed the control values. Treatment with propranolol affected neither thyroid-induced increases in systolic and diastolic blood pressure nor cardiac hypertrophy. Treatment with $0.4 \mathrm{mg} / \mathrm{Kg} /$ day propranolol (one tenth of the dose employed in the present experiment) did not produce any appreciable reduction in the thyroid-induced increase in heart rate and Ca-ATPase activity.

\section{Discussion}

The calcium stimulated ATPase activity of rabbit cardiac myosin has been demonstrated to increase by $140-280 \%$ upon treatment with subcutaneous or intramuscular injections of $10-300 \mu \mathrm{g} / \mathrm{Kg} /$ day 1 -thyroxine for 14 to

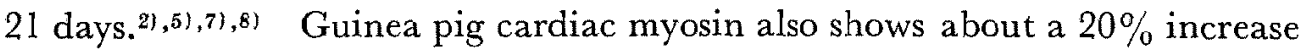
in calcium stimulated ATPase activity after treatment with intraperitoneal injections of $250 \mu \mathrm{g} / \mathrm{Kg} /$ day 1 -thyroxine.4) Our findings that thyroid-treat- 
ment results in a stimulation of myofibrillar Ca-ATPase over a period of 1 to 4 weeks are consistent with these reports. The lower magnitude of the increment in our studies is probably due to the use of a less purified fraction and differences in doses and methods of administration.

We observed no appreciable changes in the myofibrillar Mg-ATPase activity of the hyperthyroid rabbit heart. Several investigators found no changes in $\mathrm{K}^{+}$-EDTA ATPase activity of cardiac myosin after thyroxine treatment measured in the absence of calcium. ${ }^{2), 51,8)}$ In this regard, our results on $\mathrm{Mg}$-ATPase activity are compatible with these reports. Goodkind et al $^{4)}$ demonstrated that cardiac myofibrillar $\mathrm{Mg}$-ATPase activity of guinea pig was increased by about $30 \%$ after treatment with thyroxine for 8 to 21 days. This discrepancy may be due to different species and different methods for isolation of myofibrils. The latter possibility is particularly plausible because they reported that there was no appreciable stimulation of ATPase activity of myofibrils by $5 \times 10^{-6}$ to $10^{-3} \mathrm{M} \mathrm{Ca}^{2+}$. By contrast, the myofibrils employed in the present experiments showed a marked stimulation of myofibrillar ATPase activity at concentrations ranging from $10^{-5}$ to $10^{-3} \mathrm{M}$ $\mathrm{Ca}^{2+}$.

Lineweaver-Burk plots of Ca-ATPase activity showed increases in $\mathrm{Km}$ and $V_{\max }$ in myofibrils from hyperthyroid animals, indicating that myofibrillar Ca-ATPase of hyperthyroid rabbit needs more ATP to reveal half maximal activity and shows higher maximal activity than the euthyroid rabbit heart. This suggests that excess thyroid hormone may induce an increase in the absolute amount of myofibrillar Ca-ATPase or may introduce a new type of the Ca-ATPase enzyme in the cardiac muscle fiber.

Significant correlations were seen in the relationship between the CaATPase activity and the heart rate of the pooled control, hyperthyroid, and recovery rabbit (Fig. 3). It should be emphasized that when the parameters were individually analyzed with in each group, the relationship between the Ga-ATPase activity and the heart rate was the same; that is, the regression lines of the control, the thyroid tissue powder-treated and the recovery groups were virtually parallel. This indicates that treatment with excess thyroid tissue powder has reset the relationship between the Ca-ATPase and the heart rate by a linear factor without any alterations in the slopes of the relationship. Thus, characteristics of the Ca-ATPase under hyperthyroidism in the present experiments strongly suggest the appearance of a new type of Ca-ATPase enzyme. There are several findings which have demonstrated thyroid hormone-enhanced protein synthesis; for example, an increase in nuclear RNA synthesis of rats ${ }^{18)}$ and chromatin templete activity of rats. ${ }^{19)}$ Hoh et al ${ }^{20)}$ have identified three isoenzymes of rat ventricular myosin, whose synthesis 
was influenced by thyroxine. Synthesis of such isoenzymes is enhanced by thyroid hormone treatment. ${ }^{21,22)}$ Our findings arc supported by these results which provide a molecular basis for thyroid hormone-induced alterations in cardiac contractile protein.

Thyroid-induced changes in cardiac myofibrillar Ca-ATPase activity were also significantly related to an increase in the systolic blood pressure. However, they were neither related to diastolic blood pressure, nor cardiac hypertrophy (Fig. 2). Although we did not examine changes in cardiac output in the present experiments, stroke volume is not altered in paticnts with hyperthyroidism. ${ }^{23)}$ Therefore, the heart rate may be an important parameter in studies of cardiac effects of hyperthyroidism. Furthermore, both heart rate and systolic blood pressure are considered to be crucial determinants of myocardial oxygen consumption. ${ }^{24)}$ In the present experiments, both parameters were significantly correlated with myofibrillar Ca-ATPase activity. Accordingly, the increment in myofibrillar Ca-ATPase activity may be associated with an increase in myocardial oxygen consumption in hyperthyroidism.

Previous experimental results regarding participation of sympathetic activity in the pathogenesis of hyperthyroidism are equivocal. ${ }^{3,10)-12}$ ) To determine whether adrenergic stimulation participates in an increase in myofibrillar Ca-ATPase activity, adrenergic receptor blockers, phentolamine and propranolol, were employed in the present experiments. Cardiac myofibrillar $\mathrm{Ca}$-ATPase activity and cardiovascular parameters of rabbits treated with both thyroid tissue powder and phentolamine were essentially identical to rabbits treated with thyroid tissue powder alone, except for the fact that the diastolic blood pressure tended to return to the control level in the former group. By contrast, the Ca-ATPase activity and the heart rate of rabbits treated with both thyroid tissue powder and propranolol were significantly lower than the hyperthyroid rabbits. Although it is premature to conclude that induction of hyperthyroidism is mediated through beta-adrenoceptor stimulation, these results indicate that adrenergic beta-receptor activity may be related in part to the increments in cardiac myofibrillar Ca-ATPase activity and heart rate.

We have observed two types of responses of biochemical and hemodynamic factors in this experimental paradigm. First, there is a rapid onset of some thyroid effects, with a sustained maximal response during thyroid-treatment. This was related in alterations of the heart rate and myofibrillar CaATPase activity. These two factors were well correlated during the development of hyperthyroidism. The second type of response has a slow onset, with a gradual increase in some parameters during thyroid-treatment. This was observed in changes of systolic and diastolic blood pressure, and the de- 
velopment of cardiac hypertrophy. Furthermore, a lower dose of thyroid tissue powder $(25 \mathrm{mg} / \mathrm{Kg} /$ day) did not change the heart rate and the Ca-ATPase activity; however, it slightly altered the systemic blood pressure. Although the mechanisms underlying these different types of responses are unknown, it is interesting that propranolol significantly depresses the sustained maximal responses of heart rate and myofibrillar Ca-ATPase activity without affecting the gradual increases in other parameters. Since the changes in heart rate are probably secondary to those in the Ca-ATPase activity, propranolol may depress the throid-induced increase in Ca-ATPase activity. As described above, Martin et al ${ }^{22}$ demonstrated a thyroxine-induced redistribution of isoenzymes of cardiac myosin of the rabbits. If this is the case, propranolol may exert inhibitory effect on the redistribution, probably through a blockade of betaadrenergic activity.

\section{ACKNOWLEDGMENTS}

We wish to thank Dr. K. Nishi, Department of Pharmacology, Kumamoto University Medical School, for his kind and generous support to this work.

\section{REFERENCES}

1. Williams G, Braunwald E: Cardiovascular manifestation of thyroid disease. in Heart Disease, Saunders Co, New York, p 1828, 1980

2. Banerjee SK, Flink IL, Morkin E: Enzymatic properties of native and N-ethylmaleimidemodified cardiac myosin from normal and thyrotoxic rabbits. Circulat Res 39: 319, 1976

3. Buccino RA, Spann JF, Pool PE, Sonnenblick EH, Braunwald E: Influence of the thyroid state on the intrinsic contractile properties and the energy stores of the myocardium. J Clin Invest 46: 1669, 1967

4. Goodkind MJ, Dambach GC, Thyrum PT, Luchi RJ: Effect of thyroxine on ventricular myocardial contractility and ATPase activity in guinea pigs. Am J Physiol 226: 66, 1974

5. Litten RZ III, Martin BJ, Howe ER, Alpert NR, Solaro RJ: Phosphorylation and adenosine triphosphatase activity of myofibrils from thyrotoxic rabbit heart. Circulat Res 48: 495, 1981

6. Skeleton CL, Su JY, Pool PE: Influence of hyperthyroidism on glycerol-extracted cardiac muscle from rabbits. Cardiovasc Res 10: 380,1976

7. Smitherman TC, Johnson RS, Taubert K, Decker RS, Eildenthal K, Spapira W, Butsch R, Richards G: Acute thyrotoxicosis in the rabbit. Changes in cardiac myosin, contractility, and ultrastructure. Biochem Med 21 : 277, 1979

8. Yazaki Y, Raven S: Effect of the thyroid state on the cnzymatic characteristics of cardiac myosin. Circulat Res 36: 208, 1975

9. Dhalla NS, Das PK, Sharma GP: Subcellular basis of cardiac contractile failure. J Mol Cell Cardiol 10: 363, 1978

10. Christensen NJ: Plasma noradrenaline and adrenaline in patient with thyrotoxicosis and myoedema. Clin Sci Mol Med 45: 163, 1973

11. Nishizawa Y, Hamada N, Fujii S, Morii H, Okuda K, Wada M: Serum dopamine-betahydroxylase activity in thyroid disorders. J Clin Endocr Metab 39: 599, 1974 
12. Rutherford JP, Vatner SF, Braunwald E: Adrenergic control of myocardial contractility in conscious hypertrophied dogs. Am J Physiol 237: H-590, 1979

13. Solaro RJ, Pang DC, Briggs FN: The purification of cardiac myofibrils with Triton X-100. Biochim Biophys Acta 245: 259, 1971

14. Lowry $\mathrm{OH}$, Rosebrough $\mathrm{NJ}$, Farr AL, Randall RJ: Protein measurement with the Folin phenol reagent, J Biol Chem 193: 265, 1951

15. Takeo S, Fliegel L, Beamish RE, Dhalla NS: Effects of adrenochrome on rat heart sarcolemmal AT Pase activities. Biochem Pharmacol 29: 559, 1980

16. Taussky HH, Shorr E: A microcolorimetric method for the determination of inorganic phosphorus. J Biol Chem 202: 675, 1953

17. Yoshii H, Ueno S, Yano K: Radioimmunoassay for triiodothyronine and thyroxine. Fundamental and clinical studies of Amerlex $T_{3}, T_{4}$. Kakuigaku 18: 237, 1981

18. Limas CJ: Enhanced myocardial RNA synthesis in hyperthyroid rats: role of endogenous RNA polymerases. Am J Physiol 236: H-451, 1979

19. Limas CJ, Chan-Stier C: Myocardial chromatin activation in experimental hyperthyroidism in rats. Role of nuclear non-histone proteins. Circulat Res 42: 311, 1978

20. Hoh JFY, McGrath PA, Hale P: Electrophoretic analysis of multiple forms of rat cardiac myosin. Effects of hypophysectomy and thyroxine replacement. J Mol Cell Cardiol 10: 1053,1978

21. Flink IL, Rader JH, Morkin E: Thyroid hormone stimulates synthesis of a cardiac myosin isoenzyme. J Biol Chem 254: 3105, 1979

22. Martin AF, Panagi ED, Solaro RJ: Thyroxine-induced redistribution of isoenzymes of rabbit ventricular myosin. Circulat Res 50: 117, 1982

23. Wada M: Studies on cardiovascular abnormalities in hyperthyroid patients with special reference to adrenergic beta-receptor. Sapporo Med J 33: 314, 1968

24. Sarnoff SJ, Braunwald E, Weich GH Jr, Case RB, Stainsky WH, Marcruz R: Hemodynamic determinants of oxygen consumption of the heart with special reference to the Tension-Time Index. Am J Physiol 192: 148, 1958 